\title{
INTERSEÇÕES ENTRE A LINGUÍSTICA APLICADA E OS ESTUDOS DE LETRAMENTO: DESENHOS TRANSDISCIPLINARES, ÉTICOS E CRÍTICOS DE PESQUISA
}

\author{
Angela Kleiman \\ (Unicamp/CNPq) \\ Paula Baracat De Grande \\ (Unicamp)
}

RESUMO

0 artigo aborda três aspectos das pesquisas que estudam a escrita dentro da vertente sociocultural dos Estudos de Letramento inseridas no campo da Linguística Aplicada, interseção que determina dimensões epistemológicas, objetos e objetivos de pesquisa e abordagens teórico-metodológicas dos pesquisadores, como também as relações éticas com os grupos pesquisados. Com base nas pesquisas realizadas pelo Grupo Letramento do Professor, discutimos a categoria de transdisciplinaridade e as relações que têm sido desenvolvidas com o dialogismo do Círculo de Bakhtin, trazendo como exemplo os resultados de uma investigação sobre formação do professor. Em decorrência das abordagens teórico-metodológicas adotadas, discutimos um aspecto central para o Grupo a ética na pesquisa crítica, também um ponto em comum com a Linguística Aplicada. Finalmente, discutimos as interseções metodológicas, no enfoque etnográfico adotado nas pesquisas do Grupo Letramento do Professor. Concluímos comentando que a vertente da Linguística Aplicada que concebe seu objeto de pesquisa de modo transdisciplinar e adota critérios éticos como elementos de validação favorece o desenvolvimento de estudos críticos sobre a escrita nos quais tanto a escolha de problemas e contextos de pesquisa quanto as interações estabelecidas com os participantes obedecem a metas sociais dos grupos investigados.

PALAVRAS-CHAVE: transdisciplinaridade, abordagem sociocultural, ética na pesquisa, pesquisa crítica. 


\section{1 lntrodução}

A proposta deste número, que reúne num mesmo volume questões de Letramento e de Linguística Aplicada, é duplamente interessante para o linguista aplicado que realiza suas pesquisas sobre os usos da linguagem na vida social a partir da perspectiva dos Estudos de Letramento. Tantos são os pontos de contato e influências que a escolha de qual tema tratar é difícil.

Neste artigo explicitamos características da Linguística Aplicada (doravante LA) que determinam dimensões epistemológicas, rumos de pesquisa, abordagens teórico-metodológicas dos pesquisadores que estudam a escrita dentro da vertente sociocultural dos Estudos de Letramento. Primeiramente discutimos a categoria de transdisciplinaridade, e as relações que têm sido desenvolvidas com a Geografia, a Análise do Discurso nas pesquisas desenvolvidas pelo Grupo Letramento do Professor ${ }^{1}$. Complementamos a análise com outro aspecto em comum nas duas áreas em foco, a ética (e a pesquisa crítica), que também estão na base das propostas de pesquisa do grupo. Em seguida discutimos um terceiro ponto de interseção, relativo ao enfoque metodológico etnográfico. Nas conclusões, fazemos considerações sobre a vertente da LA focalizada, que concebe seu objeto de pesquisa de modo transdisciplinar e adota critérios éticos como elementos de validação e que favorece o desenvolvimento de estudos críticos sobre a escrita nos quais tanto a escolha de problemas e contextos de pesquisa quanto as interações estabelecidas com os participantes da pesquisa obedecem a metas sociais dos grupos investigados.

\section{Sintonias conceituais transdisciplinares}

Os objetos de pesquisa escolhidos pelo linguista aplicado requerem o recurso a várias áreas de conhecimento. Há vinte cinco anos, Serrani (1990) propunha como característico da natureza da pesquisa em LA a transdisciplinaridade: uma abordagem que, diferentemente do enfoque multidisciplinar, emprestaria conceitos e os devolveria às áreas de origem, problematizando as disciplinas que a constituem. Dessa interação dinâmica entre disciplinas, segundo Celani (1998), resultaria a produção de conhecimentos que contribuem tanto para a LA quanto para as demais áreas de conhecimento.

Hoje é pensamento corrente na LA que o enfoque transdisciplinar é o caminho que se mostra mais interessante para dar conta 
dos objetivos do campo, pois, primeiro, evita o risco de ecletismo de áreas muito amplas, como a LA, com diversas orientações teóricas, diversas áreas de pesquisa e de aplicação, e consequentemente com pressupostos, metodologias, objetivos e diretrizes muito diversificadas e, segundo, reforça a necessidade de teorização no campo, cujas explicações devem ser internamente consistentes e coerentes com as disciplinas convocadas.

A busca por diálogos com outras áreas do conhecimento Análise do Discurso, Estudos Culturais, Antropologia, Sociologia, Sociolinguística Interacional, entre outras - tem a ver com a própria natureza dos objetos investigados em LA. Por sua vez, a abordagem sócio-antropológica dos Estudos de Letramento requer combinações com áreas do conhecimento que favoreçam uma compreensão sócio -histórica da prática social.

Os Estudos de Letramento (New Literacy Studies) entendem as práticas de letramento como práticas sociais situadas, que variam segundo as instituições, os participantes e as relações de poder que as sustentam e, portanto, não universais. Diferentemente da grande maioria dos estudos sobre a língua escrita até o final do século passado, os Estudos de Letramento não pressupõem a existência de uma correlação entre a aquisição e posse da escrita - qualquer escrita, mas particularmente aquela legitimada por instituições como a escola, a academia, a crítica literária - e algum efeito social (como ascensão social) ou cognitivo (como inteligência superior). As pesquisas confirmam esse pressuposto. Essa concepção encontrou acolhida imediata em pesquisadores de uma área como a LA, que, desde seus primórdios, esteve voltada para problemas sociais relativos aos usos da língua oral ou escrita.

0 novo campo de pesquisa trouxe uma mudança na perspectiva dos estudos sobre os usos da escrita (especialmente na língua materna), até então nas mãos de linguistas que analisavam o texto, ou o discurso, mas não a prática social. Na formulação de problemas de pesquisa no campo dos Estudos de Letramento, considera-se o que ocorre em eventos de letramento ${ }^{2}$ e adota-se um olhar etnográfico, direcionado para as particularidades de uso da escrita nas interações entre os participantes do evento em vez de julgar o que os sujeitos não fazem a partir de uma norma pré-estabelecida, obedecida ou não em um determinado texto. Como destaca Matencio (2009), ao se constatar que, quando se fala de escrita, lida-se, sempre, com práticas sociais, 
no plural, as pesquisas desenvolvidas pelos Estudos de Letramento procuram "flagrar e compreender as atividades de leitura e escrita no âmbito das práticas sociais em que ocorrem" (MATENCIO, 2009, p. 5). A prática social, não o texto, é o objeto de pesquisa dos Estudos de Letramento. Um objeto complexo, que precisa dos aportes de diversas ciências para sua compreensão; situados na LA, os Estudos de Letramento podem usufruir do paradigma transdisciplinar da área para alcançar essa compreensão.

No início do século passado, falava-se da supremacia da língua oral, gravava-se a fala de informantes linguísticos, mas descrevia-se a estrutura dessa fala com base nas unidades analíticas que gregos e romanos inventaram para descrever a língua escrita: a frase e a oração. Surgem, então, novos enfoques analíticos com o desenvolvimento de teorias que se ocupam da língua em uso, como as Teorias da Enunciação, a Análise do Discurso. Para a análise da língua em uso com base no conceito de letramento, o qual implica uma nova forma de conceber a escrita nos estudos da linguagem, uma articulação profícua se dá entre os Estudos de Letramento e a concepção dialógica de linguagem do Círculo de Bakhtin.

\subsection{Uma articulação transdisciplinar: letramento e} círculo

Na visão de Bartlett (2003), o conceito de práticas de letramento situa os eventos de letramento e as ações individuais em um quadro social sólido, o que torna possível uma aproximação com a teoria bakhtiniana na investigação dos usos efetivos da linguagem, em diferentes grupos e por diferentes sujeitos: nesse quadro teórico, a compreensão dos usos da língua como sempre situados coaduna-se com a compreensão de que a linguagem nunca se dá no vazio, mas sempre numa situação histórica e social concreta, através da interação (VOLOCHINOV, [1929] 1985). Discutindo a natureza da língua, Volochinov ([1929] 1985, p. 123) afirma que esta é constituída pelo "fenômeno social da interação verbal, realizada através da enunciação", estendendo a noção de diálogo a toda comunicação verbal. Nessa perspectiva, qualquer discurso, escrito ou oral, é "parte integrante de uma discussão ideológica em grande escala: ele responde a alguma coisa, refuta, confirma, antecipa as respostas e objeções potenciais, procura apoio etc.".

A teorização bakhtiniana contribui para a categorização 
dos letramentos com os quais se lida em cada contexto, ao fornecer parâmetros discursivos para a postulação de categorias. 0 termo "letramento" ganhou qualificadores em pesquisas desenvolvidas em diferentes campos (letramento digital, letramento matemático, letramento científico, letramento crítico, letramento visual etc.), o que pode resultar no esvaziamento semântico do conceito. As muitas categorizações fazem perder de vista o que há de comum entre práticas de letramento e, consequentemente, perde-se a especificidade do conceito (VIANNA et. alii, 2012). A pluralidade de tipos de qualificadores dos letramentos é criticada por Bartlett (2003), a qual defende a criação de categorias "totalizantes", que considerem o que caracteriza o letramento como prática social que envolve a escrita.

No Grupo Letramento do Professor, adotamos o conceito bakhtiniano de "esfera" para caracterizar os letramentos enfocados em nossas pesquisas. A adoção de tal conceito implica considerar o tempo e lugar históricos em que os enunciados são produzidos, os participantes e as relações sociais que mantêm entre si e os gêneros utilizados na interação, focalizando como esses fatores se articulam na produção de significados no interior dessas práticas. Como argumentam Vianna et alii. (2012, s/p), "faz sentido estudarmos as práticas letradas, materializadas nos eventos de letramento, considerando-as como pertencentes aos "letramentos acadêmicos", "letramentos escolares", "letramentos do local de trabalho", uma vez que a esfera de circulação é o elemento central na modalização desses conceitos". Não faria tanto sentido qualificar os letramentos em relação a tecnologias envolvidas ou a conhecimentos e habilidades requeridos para participação no evento. Tecnologias, conhecimentos e habilidades, segundo as autoras, estão implicados nos letramentos, mas tomá-los como base para a caracterização do processo pulveriza o conceito, gerando uma infinidade de categorias, muitas delas, como letramento visual, imagético, cultural, amplas demais para defini-lo

0 conceito de esfera contempla tanto a situação específica quanto o tempo histórico (cronotopo, na perspectiva bakhtiniana) em que os enunciados são produzidos, ou seja, é situada historicamente. Conforme aponta Rojo (2013a, p.12):

o funcionamento das esferas de circulação dos discursos define os participantes possiveis da enunciação (locutor e seus interlocutores) assim como suas possibilidades (interpessoais e institucionais). Define também um leque de conteúdos temáticos possiveis (...) 
(não se pode falar de qualquer coisa em qualquer lugar) (...) 0 funcionamento de uma esfera também define "maneiras específicas de dizer/enunciar”, de discursar, cristalizadas e típicas desse campo social - os gêneros do discurso.

Entretanto, quando enfocamos a realidade social concreta, os possíveis participantes da enunciação e suas possibilidades de dizer, os conceitos de domínio ou esfera ainda podem ser muito gerais e deixar de fora elementos relevantes para entender o que ocorre em determinado contexto. Por exemplo, na pesquisa sobre as práticas de letramento formativas do professor em reuniões de corpo docente de De Grande (2015), a circunscrição da esfera que estava sendo investigada mostrou a necessidade de outros aportes teóricos: as reuniões semanais entre professoras alfabetizadoras e coordenadora pedagógica nas chamadas HTPC (Hora de Trabalho Pedagógico Coletivo $^{3}$ em uma escola pública do interior paulista pertencem à esfera escolar, já que a maioria das reuniões ocorre no espaço da escola e envolve profissionais do ensino? $\mathrm{Ou}$, alternativamente, pertencem à esfera do trabalho, por serem reuniões de formação continuada entre profissionais?

0 atributo escolar para tratar da esfera de formação do professor na escola descaracteriza a especificidade das práticas de letramento da reunião formativa. Não é qualquer prática que acontece na escola que pode ser automaticamente considerada como pertencente à esfera escolar. Por outro lado, práticas escolares como a tarefa ou dever de casa podem ser realizadas no lar, em uma biblioteca pública ou num banco de praça e, mesmo realizadas nesses locais, pertencem à esfera escolar. 0 letramento do professor ${ }^{4}$ também não se restringe ao que ocorre na escola como espaço físico - ele pode preparar aulas no lar, corrigir provas no metrô, fazer cursos de formação na universidade. Relacionar diretamente esfera a um espaço físico reduz o conceito bakhtiniano, que se refere a um campo de atividade humana caracterizado discursivamente.

\subsection{Outras articulações transdisciplinares: esfera,} espaço e interação

A esfera, como campo discursivo, não se restringe à ideia de espaço, mas sofre influências dos conjuntos de objetos e ações prototípicas do espaço em que as interações ocorrem. A relação é relevante porque determina quais as práticas e gêneros que podem 
ser atualizadas no espaço em que se desenvolvem as práticas de determinada esfera.

Foi na Geografia, no conceito de espaço de Milton Santos (2012), que De Grande (2015) encontrou a teorização que lhe permitiu refletir sobre as relações entre esferas e os locais físicos em que os eventos ocorrem. Segundo Santos, o espaço é formado por um conjunto indissociável de sistemas de objetos e sistemas de ações, reunindo a materialidade e a vida que a anima. Os sistemas de objetos e de ações que compõem um espaço sempre interagem: "de um lado, os sistemas de objetos condicionam a forma como se dão as ações e, de outro, o sistema de ações leva à criação de objetos novos ou se realiza sobre objetos preexistentes. É assim que o espaço encontra a sua dinâmica e se transforma" (SANTOS, 2012, p. 63).

A relação indissociável entre objetos e ações no enfoque de Santos não entende os aspectos físicos e os objetos de um espaço como uma coleção, ou reunião de objetos. A utilidade atual, passada ou futura deles vem de seu uso realizado por grupos humanos, das ações que os modificam. Assim, o fato de a formação em foco ocorrer, majoritariamente, na escola, com seus próprios sistemas de objetos, influencia as ações ocorridas em HTPC, e estas ações influenciam o sistema de objetos escolares. Pelo fato de se dar na escola, a HTPC pressupõe a esfera escolar e as práticas de letramento escolar, pois estas são constitutivas do trabalho docente e são, muitas vezes, objetos do discurso nos eventos formativos investigados. Contudo, os discursos que compõem a HTPC - uma esfera é definida discursivamente - não são só discursos escolares.

0 conceito de espaço leva em conta relações entre espaço e processos históricos. 0 padrão espacial, na conjugação entre um sistema de ações e um sistema de objetos, não é só morfológico, também é funcional. Os objetos podem perdurar no tempo, mas seus significados são alterados pelas relações estabelecidas em eventos concretos, situados. Assim, "as ações não são indiferentes à realidade do espaço, pois a própria localização dos eventos é condicionada pela estrutura do lugar" (SANTOS, 2012, p. 160).

0 espaço em que a formação do professor ocorre interfere nas ações das participantes nos eventos de formação e pode modificar a funcionalidade dos objetos que o compõem, como foi observado na pesquisa de De Grande (2015), quando algumas professoras participantes das reuniões semanais de HTPC na escola da pesquisa, junto 
com a coordenadora da escola, passaram a participar, quinzenalmente, de reuniões entre as coordenadoras e todas as professoras atuantes nos quintos anos da rede de ensino com o objetivo de discutir conteúdos cobrados em avaliações externas. As reuniões ocorriam em dependências da Secretaria Municipal de Ensino ou em uma unidade escolar da rede.

As reuniões realizadas na unidade escolar, somente entre professoras que lecionavam naquela escola e as reuniões interescolares, com professoras de $5^{\circ}$ ano, se diferenciavam em termos interacionais, nas relações estabelecidas entre os sujeitos e nos temas desenvolvidos. Na unidade escolar, a pauta da HTPC era variada e difusa, repleta de pontos relacionados à gestão escolar e de demandas e avisos da Secretaria de Educação. Interacionalmente, esses eventos se assemelhavam a uma aula expositiva, com a coordenadora assumindo o papel de professora e adotando o padrão IRA de interação (CAZDEN, 2001) - iniciação, resposta, avaliação, o que determinava a construção de uma relação bastante assimétrica entre ela e as professoras: a coordenadora controlava os turnos, os distribuía, avaliava a participação das professoras e a pertinência dos tópicos propostos.

Na HTPC entre professoras de $5^{\circ}$ ano e coordenadoras, a pauta tinha tópico único (um dos assuntos selecionados pelo grupo pela sua relevância para os objetivos da reunião), diretamente relacionado à formação das participantes. Em termos interacionais, a estrutura de participação se assemelhava a uma oficina, na qual uma dupla de participantes responsáveis pelo evento, que se alternava a cada encontro, introduzia o tópico e depois propunha atividades práticas, simulando o espaço da sala de aula para encenar atividades didáticas selecionadas para ensinar determinado conteúdo ou procedimento. As relações sociais estabelecidas entre as participantes eram mais simétricas: não havia controle de turnos, que eram distribuídos de forma mais equitativa entre todas as participantes. As falas das responsáveis pela organização e consecução do evento não continham avaliações dos dizeres de suas interlocutoras.

Ao entender as práticas de letramento formativas do professor em seu local de trabalho na relação com a escola como espaço e como esfera sócio-histórica, os significados construídos pelos participantes na prática social de letramento são analisados de maneira situada, relacionando lugar físico, tempo histórico, participantes e suas relações e funções no evento e nos temas construídos. 


\section{Um aparte sobre a ética: vozes do sul na} pesquisa crítica

Ouvir as vozes sociais no discurso do participante de pesquisa - no nosso caso, do professor -, exigência ética e política da LA, não é tarefa fácil quando ele já optou pelo silêncio ou pela resposta não cooperativa nas interações em que ele ocupa, novamente, o banco de aluno no espaço de formação, quaisquer que sejam seus interlocutores e os espaços ocupados, na escola, na universidade ou na delegacia de ensino.

Porém, a pesquisa em LA deve visar a objetivos transformadores e intervencionistas, fazendo escolhas que tenham impactos no mundo social, segundo Fabrício (2006). A relevância social e o compromisso político e ético fazem parte da agenda de pesquisa da área (cf. MOITA LOPES, 2006).

As pesquisas sobre o letramento, como as de nosso grupo, guiam-se por uma agenda política permanente, buscando contribuir com reflexões críticas oriundas da pesquisa aplicada e fornecer subsídios para os cursos de formação de professores que resultem numa perspectiva legitimadora do trabalho docente (CAMERON et alii, 1992; KLEIMAN \& MARTINS, 2007).

Segundo Kleiman (2002, p.189), a LA, "tal qual desenvolvida no Brasil, situa-se definitivamente na tradição de pesquisa crítica, que não procura apenas descrever e explicar, mas também se posicionar em relação ao fato examinado e, ainda, oferecer encaminhamentos e soluções para os problemas estudados”. Ao linguista aplicado não bastaria descrever línguas em perigo de extinção e afırmar que devem ser preservadas; ele se envolve na implantação de programas de formação de professores índios dessas línguas, tomando como objeto de pesquisa o próprio processo de formação desses professores na tentativa de encontrar, junto com eles, soluções para os problemas de sobrevivência simbólica da comunidade (cf. MAHER, 1998). Isso porque, na LA, um dos aspectos mais importantes da pesquisa é "a questão política de proteção dos menos poderosos, dos mais pobres, dos menos escolarizados, tomando cuidado para que nossos resultados de pesquisa não possam ser utilizados para contribuir à desvalorização desses grupos." (KLEIMAN, 2002, p. 1998).

Esse princípio estaria determinado pelos próprios objetivos do campo, que, segundo diversos pesquisadores, apresentam compro- 
missos sociais com realidades que envolvem demandas de grupos periféricos que sofrem diferentes tipos de desigualdades e de privações (CAVALCANTI, 1986; MOITA-LOPES, 2006; KLEIMAN, 2013; ROJO, 2013b).

Os professores pertencem hoje, no Brasil, a grupos periféricos quando o parâmetro de definição são as relações de poder na sociedade. Eles constituem um grupo à margem, objeto de comentários, pesquisas e tomadas de decisão de outros grupos que atuam na esfera da educação: acadêmicos, editores, burocratas, "especialistas" com espaço na mídia, como alguns economistas, psicólogos e jornalistas. Segundo Tardif (2003), apesar de sua posição estratégica na sociedade, são socialmente desvalorizados entre os diferentes grupos que atuam no campo dos saberes - pesquisadores, acadêmicos, editores, etc.

Os professores têm sua função desvalorizada pelos baixíssimos salários em comparação com outros grupos profissionais com formação superior; têm suas capacidades de leitura e escrita questionadas na mídia e na academia; muitas vezes são posicionados como técnicos, que apenas seguem materiais didáticos cada vez mais reguladores de sua prática (como os apostilados, que pretendem ditar aula a aula e o currículo) ou como alunos, que devem seguir, sem questionamento, resultados de pesquisas acadêmicas ou de documentos ofıciais relacionados à educação. E, ainda por cima, são responsabilizados pelo fracasso do aluno em avaliações governamentais e recebem tratamento violento por parte do estado que os emprega ${ }^{5}$.

Essa representação negativa é questionada nas pesquisas do Grupo Letramento do Professor, que partem do pressuposto de que, ao analisar qualquer prática profissional do professor, o processo de investigação deve considerar o letramento situado, i.e., o letramento no local do trabalho, ou seja, as práticas sociais de uso da escrita realmente necessárias ao professor para exercer sua profissão.

Os pesquisadores do grupo vão mais longe, pois defendem a inviabilidade de um linguista aplicado brasileiro esquecer o lugar em que são produzidos conhecimentos, identidades e relações em jogo na pesquisa: "desde um espaço-tempo que sofreu séculos de colonização, um lócus que marca os nossos corpos, as nossas palavras" (KLEIMAN, 2013, p. 43). A proletarização do professor, a exclusão, o conflito intercultural são propostos como temas importantes para o linguista aplicado que quer investigar a formação docente, de um lugar privilegiado, "com olhos do sul, para o sul". Por isso, seria cada vez mais urgente desenvolver e divulgar pesquisas em LA alinhadas a uma postura ética em relação aos grupos de periferia, 
que inclui o professor ${ }^{6}$. Esse alinhamento resultaria em

uma Linguística Aplicada crítica com uma agenda que, em consonância com sua vocação metodológica interventiva, rompe o monopólio do saber das universidades e outras instituições que reúnem grupos de pesquisadores e intelectuais e toma como um de seus objetivos a elaboração de currículos que favoreçam, por um lado, a apropriação desses saberes por grupos na periferia dos centros hegemônicos e, por outro, a legitimação dos saberes produzidos por esses grupos (KLEIMAN, 2013, p.41).

Com a finalidade de contribuir para a construção dessa agenda e subsidiar possíveis mudanças em currículos que favoreçam saberes construídos por grupos não hegemônicos, as pesquisas sobre o letramento do professor buscam trazer e compreender as vozes do professor, geralmente subalternas, pois desvalorizadas e silenciadas, em relação a outros grupos que se cruzam nas discussões sobre educação. Subalterno, ou periférico, é aqui entendido como posicionado inferiormente em relação a quem detém o monopólio do saber, a centros hegemônicos que ditam o que conta como conhecimento (SOUSA SANTOS, 2004) ou o que conta como letramento (STREET, 2003). Isto não quer dizer que os sujeitos não tenham possibilidade de exercer agência social e subverter as relações de poder. São exatamente esses espaços e brechas construídos pelos sujeitos para exercerem agência os que possibilitam outro olhar, que desafie a representação negativa que se faz dos professores brasileiros e que nos obrigam a refletir sobre as formações oferecidas pela universidade.

Para desenvolver uma agenda comprometida com esses grupos, Kleiman (2013) defende a proposta de pesquisa do Programa Modernidade/Descolonialidade ${ }^{7}$, cujos membros argumentam a favor de uma virada epistemológica 'para' a periferia e 'a partir da' periferia, a fim de visibilizar participantes de movimentos sociais feministas, étnico/raciais, gays, dos sem-terra, sem-teto, sem-escrita, "ou ainda, no caso dos alfabetizadores e professores, daqueles sem movimentos sociais que os acolham e os fortaleçam" (KLEIMAN, 2013, p. 43). Essa virada implica trazer para a pesquisa os sujeitos socio-históricos de nossa realidade social e suas epistemes em relação à sua própria formação e atuação profissionais, legitimando os saberes por eles produzidos.

Aliando as investigações etnográficas e situadas próprias dos Estudos de Letramento ao caráter crítico e ético das pesquisas em LA, os objetivos do Grupo Letramento do Professor envolvem, mais do que 
observar e descrever o que os sujeitos fazem com a escrita situadamente, legitimá-los e considerar suas vozes pertinentes nas discussões sobre formação docente, currículo e políticas públicas de educação.

A avaliação do que faz o professor da escola básica em geral se baseia em parâmetros acadêmicos, principalmente os relacionados à escrita. Esta, como mostram pesquisas do grupo Letramento do Professor, pode se tornar um poderoso mecanismo de constituição da subalternidade dos docentes, como também pode ser usada para subverter essa subalternidade (KLEIMAN, 2006, 2013; VÓVIO, 2007; VALSECHI et al., 2014; KLEIMAN, VIANNA, DE GRANDE, 2013). Partindo desse lugar, buscamos perspectivas que permitam ouvir o professor, considerando como produtor de conhecimentos que podem ser legitimados e integrados em formações oferecidas por instituições de prestígio (assim, constroem-se novos elos com o dialogismo do Círculo de Bakhtin, teoria enunciativo-discursiva já mencionada na seção anterior). Os Estudos de Letramento se beneficiam ao incorporar conexões entre poder e conhecimento (BARTLETT, 2003), trazendo um enfoque sociológico para as pesquisas sobre a escrita por diferentes grupos sociais, principalmente aqueles subalternizados.

Uma grande contribuição da vertente sociocultural dos Estudos de Letramento para pesquisas desenvolvidas dentro de uma abordagem crítica e ética, em consonância com os princípios da pesquisa em LA, é o fato de trazer para o primeiro plano os discursos sobre o próprio fazer dos participantes das pesquisas que, como já mencionado, frequentemente têm suas vozes silenciadas e suas concepções invisibilizadas. Efetivamente, o foco nos modos como os participantes das pesquisas constroem os eventos observados e se constroem nesses eventos permite mostrar as agentividades e heterogeneidades (VÓVIO, 2007; VÓVIO, DE GRANDE, 2010) construídas, desafinado as vozes que os representam de maneira subalterna.

\section{Percursos metodológicos afins}

0 redimensionamento e reelaboração de referenciais teóricos nos vários campos de estudo que buscam interpretar o mundo social, como no caso do enfoque transdisciplinar da LA e dos Estudos de Letramento, apoiam-se em metodologias que levam em conta o contexto em que os dados são gerados e que procuram compreender esses dados e seus contextos em toda sua riqueza, complexidade e profundidade (MASON, 1998). 
A relação entre abordagem metodológica e natureza do objeto de pesquisa é, segundo Silva (2003), dialética: a dimensão metodológica ajuda a delimitar o objeto de pesquisa e a visualizar a perspectiva de análise e, por sua parte, a concepção da natureza do objeto de estudo aponta para paradigma em que a pesquisa será desenvolvida. Esse paradigma, na LA e nos Estudos de Letramento, é qualitativo e interpretativo, pela sua preocupação em saber como o mundo social é interpretado, entendido e produzido (MASON 1998). A metodologia qualitativo-interpretativista surgiu simultaneamente na investigação de diversos objetos (identidade, interação de sala de aula, entre outros), que requerem, segundo Street (1993, p. 1), "explicações detalhadas, aprofundadas de práticas em diferentes contextos culturais”. Uma multiplicidade de letramentos que a via etnográfica pode revelar.

Segundo Magnani (2002, s/n), que procura na etnografia o método que lhe permitira compreender a dinâmica sociocultural da cidade, é evidente a viabilidade do método para o estudo das problemáticas contemporâneas. Ele afirma que

não há necessidade de muitos malabarismos pós-modernos para aplicar com proveito a etnografia a questões próprias do mundo contemporâneo e da cidade, em particular: desde as primeiras incursões a campo, a antropologia vem desenvolvendo e colocando em prática uma série de estratégias, conceitos e modelos que, não obstante as inúmeras revisões, criticas e releituras (quem sabe até mesmo graças a esse continuado acompanhamento exigido pela especificidade de cada pesquisa) constituem um repertório capaz de inspirar e fundamentar abordagens sobre novos objetos e questões atuais.

Na perspectiva da LA e dos Estudos de Letramento, ambos com interesse em entender os usos da linguagem na construção de relações sociais baseadas no poder; nas conexões entre poder e conhecimento; na construção de conhecimentos e de identidades na e pela interação em situações concretas de comunicação intercultural no mundo contemporâneo, faz ainda menos sentido acreditar que a via etnográfica precisa de manipulações malabaristas pós-modernas para se impor como a metodologia que melhor contribui para abordar esses problemas de pesquisa.

A natureza da explicação pela via etnográfica permite, de acordo com Magnani (2002), reorganizar dados percebidos como fragmentários, informações ainda dispersas, indícios soltos, num 
novo arranjo que não é aquele do participante da situação, mas que parte dele e o levaria em conta. Também não seria mais o olhar com o qual o pesquisador inicia a pesquisa, porque "este novo arranjo carrega as marcas de ambos: mais geral do que a explicação nativa, presa às particularidades de seu contexto, pode ser aplicado a outras ocorrências; no entanto, é mais denso que o esquema teórico inicial do pesquisador, pois tem agora como referente o 'concreto vivido"” (s/n).

Deve-se às abordagens etnográficas da vertente sócio-antropológica dos Estudos de Letramento o reconhecimento de uma realidade social em que coexistem múltiplos letramentos, não uma única habilidade neutra e técnica (mas múltiplas e heterogêneas formas de utilizar a escrita) (STREET, 1984, 1993; KLEIMAN, 1995; BARTON, 2000).

A abordagem etnográfıca é a opção metodológica nas pesquisas do Grupo Letramento do Professor, por entender que a formação do professor é um processo identitário construído em situações concretas de uso da linguagem - os eventos de letramento - e que o letramento do professor não é um "mero instrumento para realização do trabalho", e sim um aspecto constituinte de sua atuação profissional (KLEIMAN, 2009, p. 21).

Pesquisas na perspectiva dos Estudos de Letramento objetivam descrever e compreender o que os sujeitos fazem com a escrita em diferentes contextos, o que conta como letramento situadamente e como os sujeitos agem nesses contextos, enfocando o que dizem sobre si mesmos, sobre as práticas sociais das quais participam, (re)construindo sua identidade, mesmo que de modo circunstancial em uma situação comunicativa (VÓVIO, 2007; VÓVIO, DE GRANDE, 2010; VALSECHI, 2009). A entrada do pesquisador nas próprias comunidades dos grupos sociais participantes das pesquisas, como nos movimentos urbanos de jovens ativistas negros criando novos gêneros em práticas de letramento, na pesquisa de Souza (2009), de negros lutando pelo reconhecimento de escrituras de posse da terra, e de alunos cotistas indígenas e negros nas pesquisas de Sito (2010; 2014), de alfabetizadoras leigas em comunidades de risco no estado de São Paulo, na pesquisa de Vóvio (2007), fornece contrapontos relevantes para nossa compreensão das realidades observadas nas práticas de letramento escolar e acadêmico.

E, nessas perspectivas de análise, são reforçados os elos transdisciplinares com o dialogimo bakktiniano, pois o foco nessas pesquisas também recai nos usos da linguagem, na construção de realidades 
na interação e nas relações de poder que se refletem e refratam nos enunciados concretos. Trata-se, portanto, de inserções importantes para a compreensão de outros sistemas de conhecimentos e para a construção de explicações coerentes, não fragmentadas, da realidade, derivadas da abordagem transdisciplinar.

\section{Considerações finais}

A compreensão dos objetos de pesquisa estudados pelo linguista aplicado demanda o recurso a várias áreas de conhecimento. Configura-se, em consequência, a transdiciplinaridade como um caminho possivel para dar conta da natureza e objetivos do campo.

Inserida na LA, a pesquisa do Grupo Letramento do Professor, da vertente sociocultural dos Estudos de Letramento, recorre a conceitos de diferentes áreas para compreender os contextos complexos pesquisados, principal, mas não exclusivamente, relacionados à formação e à atuação docentes. A teoria bakhtiniana auxilia a relacionar a perspectiva situada dos Estudos de Letramento a relações de poder construídas sócio-historicamente e marcadas nos enunciados dos participantes das pesquisas.

A articulação transdisciplinar mais abrangente é com o dialogismo, do Círculo de Bakhtin, pela concepção de linguagem; porém, também são importantes articulações mais específicas, determinadas por eventos sui generis em realidades locais específicas. A cada novo contexto investigado, o objeto pesquisado pode vir a demandar do linguista aplicado a busca por novos aportes teóricos que possam contribuir para sua compreensão. Na pesquisa sobre práticas de letramento formativas do professor no local de trabalho, por exemplo, De Grande (2015) utilizou o conceito de espaço de Santos (2012), do campo da Geografia, para adensar o conceito de esfera da teoria bakhtiniana. 0 conceito permitiu enfatizar o caráter situado de toda prática de letramento, destacando aspectos da realidade social concreta investigada.

A inserção das pesquisas informadas pelos Estudos de Letramento no campo da LA favorece a adoção da postura crítica e ética comum a ambos. Os objetivos da LA e das pesquisas do Grupo se definem de modo a contemplar compromissos sociais relativos a demandas de grupos periféricos, que sofrem diferentes tipos de desigualdades e discriminação. As pesquisas buscam trazer as vozes desses grupos para revelar relações de poder, suas possíveis subver- 
sões e para refletir sobre práticas socialmente poderosas, como as da própria academia. Nos Estudos de Letramento especificamente, tal postura tem sido fortalecida com os aportes dos estudos descoloniais.

0 conjunto de regras de conduta ética profissional do pesquisador da linguagem, que decorrem da concepção da natureza do seu objeto, por um lado, e das regras de conduta ética da sociedade democrática, que determinam o respeito mútuo entre pesquisador e pesquisado, por outro, são complementadas, nas pesquisas da LA e dos Estudos de Letramento, por um conjunto de princípios gerais que definem uma postura política de respeito, ajuda e promoção ou avanço dos grupos pesquisados (KLEIMAN, 2002). Isso também envolve, como um dos resultados da pesquisa, a visibilização de estratégias de resistência dos grupos pesquisados e, talvez, contribua para reorientar programas, políticas e formações oferecidas pelos órgãos que têm o poder de implantá-los, a partir da ótica do outro na pesquisa, a desses grupos.

\section{ABSTRACT}

The paper discusses three aspects in New Literacies Studies research in Brazil, as developed by researchers from an Applied Linguistics perspective. This perspective contributes to determine epistemological, theoretical, and methodological issues in literacy research, as well as ethical issues in regard to the relationships established with the groups who participate in the research. Taking examples from our research group, known as Teacher Literacy Research Group (created in 1991), we discuss transdisciplinary relationships built between Literacy and Dialogism as developed by Bakhtin and his Circle. Another intersecting point between Applied Linguistics and Literacy Research discussed in the paper is the relation between ethics and research in the two fields; a third one has to do with the methods adopted: as in several other studies in Applied Linguistics, in literacy studies, ethnography has been the preferred methodology. We conclude pointing out that an approach that conceives its object in a transdisciplinary manner and adopts ethical criteria as a research validation element favors the development of critical studies about writing in which the choice of problems and research contexts support the social goals of the investigated groups. 
KEYWORDS: transdisciplinary, sociocultural approach, ethics, critical research.

\section{NOTAS}

${ }^{1}$ Base Lattes http://dgp.cnpq.br/dgp/espelhogrupo/5189323694490294 . Criado em 1991. Atualmente, integram o grupo pesquisadores (e seus alunos), de oito universidades: UNICAMP, PUC-Minas, UNEB, UFBA, UFRN, UFPB, UNITAU e UNIFESP. www.letramento.iel.unicamp.br

${ }^{2}$ Evento de letramento, conceito cunhado por Heath (1982), é entendido como "ocasiões em que a língua escrita é parte integrante da natureza das interações entre os participantes e de suas estratégias e processos interpretativos" (p. 50).

${ }^{3}$ A HTPC é o período destinado, nas escolas públicas paulistas, a reuniões entre o corpo docente da escola e a coordenação pedagógica com finalidades diversas relacionadas à formação e à atuação docentes e à gestão escolar. Em 2012, passou a ser chamada de ATPC (Aula de Trabalho Pedagógico Coletivo) para compor a remuneração do professor, que ocorre por hora-aula.

${ }^{4}$ Entendemos letramento do professor como as práticas sociais de uso da escrita que ele realmente precisa para exercer sua profissão e melhorar sua prática didática (KLEIMAN, 2001).

${ }^{5} \mathrm{~A}$ indiferença em relação ao movimento de greve dos professores das escolas estaduais paulistas e a violência empregada pelo Estado do Paraná em manifestações de seus professores estaduais em 2015 são exemplo desse tratamento recebido pelo docente brasileiro.

${ }^{6} \mathrm{E}$ que também nos inclui, se considerarmos a relação entre a ciência dos países do Norte e a dos países do Sul.

${ }^{7}$ Orientado pelas perspectivas teórico-metodológicas de sociólogos e filósofos voltados para o sul, como, por exemplo, Escobar (2003), Quijano (2007); Mignolo (2007) entre muitos outros.

\section{REFERÊNCIAS}

BARTLETT, L. Social Studies of Literacy and Comparative Education: Intersections. Current Issues in Comparative Education, Teachers College, Columbia University, Vol. 5(2), 2003. 
CAMERON, D. FRAZER, E. HARVEY, P., RAMPTON, M.B.H., \& RICHARDSON, K. (1992) Researching Language. Issues of Power and Method. London: Routledge, 1992.

CAZDEN, C. Classroom discourse: The Language of Teaching and Learning,2 ed., Heinemann Press, 2001.

CELANI, M. A. A. A transdisciplinaridade na Linguistica Aplicada no Brasil. In: SIGNORINI, I.; CAVALCANTI Marilda C. (Orgs.). Linguística Aplicada e Transdisciplinaridade: questões e perspectivas. Campinas: Mercado de Letras, 1998, p. 98-107.

DE GRANDE, P. B. Formação continuada no local de trabalho do professor: possibilidades de agência e construção de sentidos para a docência. Tese de Doutorado em Linguística Aplicada. Unicamp, Campinas, 2015.

ESCOBAR, Arturo. Mundos y conocimientos de otro modo». El programa de investigación de modernidad/colonialidad latinoamericano. Tabula Rasa. Bogotá - Colômbia, No.1, p. 51-86, jan-dez 2003.

HEATH, S.B. What no bedtime story means: narrative skills at home and school. Language and Society, (11), p. 49-76, 1982.

KLEIMAN, Angela B. "Modelos de letramento e as práticas de alfabetização na escola”. In: KLEIMAN, A. B. (Org.) Os significados do letramento. Uma perspectiva sobre a prática social da escrita. Campinas, SP: Mercado de Letras, 1995, p. 15-61.

. Letramento e formação do professor: quais as práticas e exigências no local de trabalho? In: KLEIMAN, A. B. (Org.). A Formação do Professor. Perspectivas da Lingüística Aplicada. Campinas: Mercado de Letras, 2001, p. 39-68.

.A interface de questões éticas e metodológicas na pesquisa em Linguística Aplicada, In: da Silva, Denize E.G. \&t Vieira, Josênia A (Orgs). Análise do Discurso Percursos Teóricos e Metodológicos. Brasília: UnB, Editora Oficial do Instituto de Letras, Editora Plano, 2002p. 187-202.

. Projetos dentro de projetos: ensino-Aprendizagem da escrita na formação de professores de nível universitário e de outros agentes de letramento. Scripta, Belo Horizonte, v. 13, n. 24, p. 17-30, $1^{\circ}$ sem. 2009.

Agenda de pesquisa e ação em Linguística Aplicada: problematizações. In: MOITA LOPES, L. P. Linguística Aplicada na modernidade recente: festschrift para Antonieta Celani. São Paulo: Parábola, 2013.

KLEIMAN, A. e MARTINS, M. S. C. Formação de professores: a contribuição das instâncias administrativas na conservação e na transformação de práticas docentes. In: KLEIMAN, A. e CAVALCANTI, M. C. (orgs.) Lingüistica Aplicada: suas faces e interfaces. Campinas, SP: Mercado de Letras, 2007. 
KLEIMAN, A., VIANNA, C., DE GRANDE, P. B. "Sem querer ir contra pessoas tão ilustres...”: construção e negociação identitárias do professor entre discursos de (des)legitimação. Scripta. V.17, n. 32, 2013.

MAGNANI , José G. C. De perto e de dentro: notas para uma etnografia urbana. Revista Brasileira de Ciências Sociais, vol.17, no.49, June 2002, p. Acessível em: http://dx.doi.org/10.1590/S0102-69092002000200002

MAHER, T. M. . A Educação do Entorno para a Interculturalidade e o Plurilinguismo. In: Kleiman \& Cavalcanti. (Org.). Lingüistica Aplicada - suas faces e interfaces. Campinas: Mercado de Letras, 2007, v., p. 255-270.

MASON, J. Qualitative Researching. London, England: SAGE Publications, 1998.

MATENCIO, M.L.M Estudos do letramento e formação de professores: retomadas, deslocamentos e impactos. Caleidoscopio. V.7, n.1, p. 5-10, jan/abr 2009. MIGNOLO, W.. El pensamiento decolonial: desprendimiento y apertura. Un maniûesto. IN: CASTRO-GÓMEZ, Santiago; GROSFOGUEL, Ramón (Orgs.). El giro decolonial. Reûexiones para una diversidad epistémica más allá del capitalismo global. Bogotá: Siglo del Hombre Editores, Univ Central, Instituto de Estudios Sociales Contemporáneos e Pont Univ Javeriana, Instituto Pensar, 2007, p. 29-46.

MOITA-LOPES, L.P. Uma lingüística aplicada mestiça e ideológica. Interrogando o campo aplicado como lingüista aplicado. In: Moita Lopes, L. P. (Org.) Por uma Lingüistica Aplicada Indisciplinar. São Paulo: Parábola Editorial, 2006. QUIJANO, Aníbal. Colonialidade do poder e classificação social. IN: CASTRO-GÓMEZ, Santiago; GROSFOGUEL, Ramón (Orgs.). El giro decolonial. Reûexiones para una diversidad epistémica más allá del capitalismo global. Bogotá: Siglo del Hombre Editores, Univ Central, Instituto de Estudios Sociales Contemporáneos e Pont Univ Javeriana, Instituto Pensar, 2007, p. 93-126.

ROJO, R. A teoria dos gêneros discursivos do Círculo de Bakhtin e os multiletramentos. In: (org.). Multiletramentos e as TICs: Escol@Conect@d@. São Paulo: Parábola, 2013a.

. Caminhos para a LA: política linguística, política e globalização. In: Nicolaides, C., Silva, K. A., Tilio, R. e Hilsdorf, C. (Orgs.). Politica e Politicas Linguísticas. Campinas, SP: Pontes, 2013b.

SANTOS, M. A Natureza do Espaço: Técnica e Tempo, Razão e Emoção. 4ed. São Paulo: Editora da Universidade de São Paulo, 2012.

SERRANI, Silvana M. Transdisciplinaridade e discurso em Linguística Aplicada. Trabalhos em Linguística Aplicada, v. 16, 1990, p. 39-46.

SILVA, S. B. B. Formação de Professores e PCN: um olhar sobre a leitura e o material de leitura. Tese (Doutorado), Linguística Aplicada, Instituto de Estudos da Linguagem, Universidade Estadual de Campinas, Campinas, SP, 2003. 
SITO, Luanda. . "Disputas y diálogos en torno al concepto de 'acciones afirmativas' para la educación superior en Brasil”. Universitas Humanistica, v. 77, p. 251-273, 2014.

SOUZA-SANTOS, B. O Fórum Social Mundial. Manual de Uso. Madison, 2004. Disponivel em: http://www.ces.uc.pt./bss/documentos/fsm/pdf

STREET, B. Literacy in theory and practice. Cambridge: Cambridge University Press, 1984.

. The new literacy studies. In: STREET, B. (org.). Cross-cultural approaches to literacy. Cambridge: Cambridge University Press, 1993.

TARDIF, M. Saberes docentes e formação profissional. 3 ed. Petrópolis, RJ: Vozes, 2003.

VALSECHI, M. C., SITO, L.S., DE GRANDE, P. B., PEREIRA, S.L., VIANNA, C.S.D. Legitimação dos participantes e rompimento de assimetrias: contribuições do grupo letramento do professor para o campo dos estudos de letramento. In: i. Belo Horizonte, MG, 2014.

VIANNA, C. A., SITO, L.S., VALSECHI, M. C., PEREIRA, S.L. Do Letramento aos Letramentos: desafios na aproximação entre o letramento acadêmico e o letramento do professor, mimeo, 2012.

VOLOCHINOV. Marxismo e Filosofia da Linguagem. São Paulo: Hucitec, 1985. VÓVIO, C. L. Entre discursos: sentidos, práticas e identidades leitoras de alfabetizadores de jovens e adultos. Tese (Doutorado), Linguística Aplicada, Instituto de Estudos da Linguagem, Universidade Estadual de Campinas, Campinas, 2007. VÓVIO, C.L.; DE GRANDE, P.B. 0 que dizem as educadoras sobre si: construções identitárias e formação docente. In: VÓVIO, C.L.; SITO, L.S.; DE GRANDE, P.B. LetramentoS: rupturas, deslocamentos e repercussões de pesquisas em Linguística Aplicada. Campinas: Mercado de Letras, 2010.

Recebido em 30 de maio de 2015

Aprovado em 15 de junho de 2015 